\title{
A POLÍTICA ESTADUAL DE AMPLIAÇÃO DO TEMPO ESCOLAR NO PARÁ: LENTO PROCESSO DE EFETIVAÇÃO
}

\author{
THE STATE POLICY OF ENLARGEMENT OF SCHOOL TIME \\ IN PARÁ: SLOW EFFECTIVENESS PROCESS
}

\section{LA POLÍTICA ESTATAL DE AMPLIACIÓN DEL TIEMPO ESCOLAR EN PARÁ: PROCESO DE EFECTIVO LENTO}

\author{
Reginaldo do Socorro Martins da Silva ${ }^{1}$ \\ https://orcid.org/0000-0002-2765-8334 \\ Ney Cristina Monteiro de Oliveira ${ }^{2}$ \\ https://orcid.org/0000-0002-8091-5213

\footnotetext{
${ }^{1}$ Universidade Federal do Pará, Belém, Pará - Brasil. E-mail: reginaldomss13@ gmail.com.

${ }^{2}$ Universidade Federal do Pará, Belém, Pará - Brasil. E-mail: neycmo@ufpa.br.
}

\begin{abstract}
Resumo
A educação em tempo integral é um tema recorrente nas discussões em vários segmentos no contexto da educação brasileira, com especial destaque para os estudos que consideram a relação entre as políticas públicas e as experiências educativas nas escolas de tempo integral. Nesse sentido, o artigo tem como objetivo apresentar o processo histórico de implantação da política de tempo integral nas escolas públicas no estado do Pará como ação recente. A pesquisa é caracterizada por enfoque qualitativo, tendo como procedimento metodológico a pesquisa documental. As fontes da coleta de dados foram os documentos oficiais da educação do Pará no período de 2007-2018 (PEE-PA/2010 e PEE-PA/2015; as Resoluções nº 002/2012 e n ${ }^{\circ}$ 003/2012 - GS/SEDUC), o Censo Escolar/17 e o portal SEDUC-PA/18. Os dados foram interpretados sob a técnica da análise de conteúdo. Os resultados apontam para um processo lento de adesão dos projetos governamentais à pauta do tempo integral. Além do mais, os programas foram implantados sem o devido diagnóstico das condições estruturais das escolas e sem o preparo da comunidade escolar quanto às novas exigências e desafios para o sucesso de um novo projeto de qualidade na escola pública com a oferta de atividades em tempo integral.
\end{abstract}

Palavras-chave: Educação. Política Pública. Escola de Tempo Integral.

\section{Abstract}

Full-time education is a recurring theme in the discussions in various segments in the context of Brazilian education, with special emphasis on studies that consider the relationship 
between public policies and educational experiences in full-time schools. In this sense, the article aims to present the historical process of implementation of the policy of full time in Public Schools in the State of Pará as a recent action. The research is characterized by a qualitative approach, having as methodological procedure the documentary research. The source of the data collection was the official education documents of Pará, in the period from 2007-2018 (PEE-PA/2010 and PEE-PA/2015, Resolutions no. 002/2012 and no. 003/2012GS/SEDUC), the School Census/17 and the SEDUC-PA/18portal. The data were interpreted under the technique of content analysis. The results point to a slow process of adherence of government projects to the full-time agenda. Moreover, the programs were implemented without proper diagnosis of the structural conditions of the schools and without the preparation of the school community regarding the new requirements and challenges for the success of a new quality project in the public school with the provision of full-time activities.

Keywords: Education. Public Policy. Full-Time School.

\section{Resumen}

La educación de tiempo completo es un tema recurrente en las discusiones en varios segmentos en el contexto de la educación brasileña, con especial énfasis en los estudios que consideran la relación entre las políticas públicas y las experiencias educativas en las escuelas de tiempo completo. En este sentido, el artículo pretende presentar el proceso histórico de implementación de la política de tiempo completo en las escuelas públicas del estado de Pará como una acción reciente. La investigación se caracteriza por un enfoque cualitativo, teniendo como procedimiento metodológico la investigación documental. Las fuentes de la recolección de datos fueron los documentos educativos oficiales de Pará en el período 2007-2018 (PEE-PA/2010 y PEE-PA/2015, Resoluciones no. 002/2012 y no. 003/2012-GS/SEDUC), el Censo Escolar/17 y el portal SEDUC-PA/18. Los datos fueron interpretados bajo la técnica de análisis de contenido. Los resultados apuntan a un lento proceso de adhesión de los proyectos gubernamentales a la agenda de tiempo completo. Además, los programas se implementaron sin un diagnóstico adecuado de las condiciones estructurales de las escuelas y sin la preparación de la comunidad escolar con respecto a los nuevos requisitos y desafíos para el éxito de un nuevo proyecto de calidad en la escuela pública con la provisión de actividades de tiempo completo.

Palabras clave: Educación. Política Pública. Escuela de Tiempo Completo.

\section{Introdução}

Este texto é oriundo de pesquisa do mestrado intitulada "A educação integral em tempo integral na escola privada: experiências pioneiras na cidade de Belém”. O recorte que trouxemos neste artigo se concentra no contexto histórico do surgimento das primeiras experiências de escolas públicas de tempo integral no estado do Pará e objetiva analisar as características dos programas oficiais e das políticas públicas estaduais que se apresentavam com essa proposta. Dessa forma, delimitamos dois momentos históricos em que, sob diferentes formatos organizacionais de tempo-espaço, foram implementados programas de 
escolas de tempo integral pelos governos estaduais: um primeiro momento, durante o governo do Partido dos Trabalhadores (PT), entre 2007 e 2010, e um segundo momento, entre 2011 e 2018, no governo do Partido Social Democrata do Brasil (PSDB).

Este artigo faz uma breve revisão bibliográfica e um estudo documental acerca do assunto, buscando entender as características dos programas de escola de tempo integral outrora implementados pelas políticas públicas no estado do Pará.

Para atender ao objetivo delineado neste texto, realizamos o seguinte percurso metodológico: 1. pesquisa bibliográfica referenciada nos estudos de Cavaliere (2002-2017), Coelho (2002-2018), Gadotti (2013), Guará (2006), Libâneo (2006), Maurício (2009), Moll (2009-2012), Paro (1988; 2009), Ribeiro (1986), Saviani (2013), entre outros; 2. estudo documental com base em legislações educacionais nacional (BRASIL, 2001-2017) e paraense (PARÁ, 2008-2018); 3. análise de dados com base na perspectiva de Bardin (2011) e Franco (2012).

Os dados analisados revelam que, em se tratando da implementação da escola de tempo integral no estado do Pará, o processo ocorre de forma lenta e interessada, estando em função de políticas públicas mais eleitoreiras do que políticas de Estado que promovam uma educação de qualidade social para todos.

Assim, o presente artigo foi estruturado em quatro seções, sendo a primeira introdutória. A segunda discute especificamente o contexto histórico do surgimento das escolas de tempo integral ${ }^{1}$ no estado do Pará. A terceira trata dos avanços relativos dos programas que implementaram as escolas de tempo integral no Pará. Por fim, apresentamos as considerações, que abordam a apreensão das duas categorias - contexto e implantação - na perspectiva das políticas públicas para a escola de tempo integral com o intuito de colaborar com o debate em questão.

A fim de iniciarmos a discussão, questionamos: como surgiram as escolas de tempo integral no estado do Pará?

\footnotetext{
${ }^{1}$ O recorte histórico considerado será o período de 2007 a 2018. Entendemos o tempo integral da forma como está definido oficialmente nos documentos do FUNDEB, PNE I e PME, equivalente a um tempo igual ou maior que 7 horas.
} 


\section{0 contexto histórico do surgimento das escolas públicas de tempo integral no estado do Pará}

O processo de implantação das escolas públicas de tempo integral no estado do Pará teve seu embrião no ano de 2008, a partir da elaboração da política educacional sob a marca de Educação de Qualidade Pará Todos. Tratava-se de um documento orientador às escolas da rede pública estadual e que expressava os anseios de um coletivo social paraense, fruto dos debates da I Conferência Estadual de Educação realizada no mesmo ano.

Dessa forma, como resultado dos trabalhos daquela conferência, foi elaborado um documento que apresentava os pressupostos - diretrizes, metas e objetivos - para a educação básica intitulado “A Educação Básica no Pará: elementos para uma política democrática e de qualidade Pará todos” (PARÁ, 2008). Esse documento era basilar para as escolas da rede pública no sentido de aprofundar e materializar novos rumos à educação básica no estado, demandando, assim, elementos para a construção do Plano Estadual de Educação (PARÁ, 2010), que foi finalizado em julho de 2010.

De acordo com Costa (2015) a fundamentação legal à implantação do Projeto Escola de Tempo Integral da SEDUC-PA surgiu, no âmbito da educação paraense, paralelamente ao calor das discussões em escala nacional das metas do Plano Nacional de Educação I (PNE I) (2001-2010), que, entre outras metas, destacava de forma específica a jornada escolar de tempo integral e estabelecia (BRASIL, 2001):

\footnotetext{
Ampliar, progressivamente a jornada escolar visando expandir a escola de tempo integral, que abranja um período de pelo menos sete horas diárias, com previsão de professores e funcionários em número suficiente (objetivo e meta 21).

Prover, nas escolas de tempo integral, preferencialmente para as crianças das famílias de menor renda, no mínimo duas refeições, apoio às tarefas escolares, a prática de esportes e atividades artísticas, nos moldes do Programa de Renda Mínima Associado a Ações Socioeducativas (objetivo e meta 22).
}

A origem do projeto Escola de Tempo Integral da SEDUC-PA remonta ao primeiro apontamento legal com a implantação da Lei $n^{\circ} 7.441$, de 2 de julho de 2010, que aprovou o Plano Estadual de Educação com caráter decenal. O referido documento apresentava, na seção II, intitulada Diretrizes, Objetivos e Metas para a Educação Paraense, “orientações para o 
progressivo atendimento em tempo integral para as crianças de 0 a 5 anos de idade, inseridas na educação infantil". Também revelava, como objetivos e metas, a aspiração de "viabilizar a implantação das Escolas em Tempo Integral para o ensino fundamental de nove anos obrigatório com o início aos seis anos de idade, implementado, gradativamente, nas escolas" (PARÁ, 2010).

A Secretaria de Estado de Educação do Pará iniciou o processo de oferta de educação integral em 2009 mediante a adesão ao programa nacional Mais Educação de 2007 e avançou, em 2012, por meio da implantação do projeto da escola de tempo integral. Ressaltamos que o projeto inicial de escola de tempo integral no Pará sofreu alterações em sua concepção, com a mudança de gestão no governo do estado no ano de 2011.

Dessa forma, a partir de 2012, os novos documentos que passaram a orientar a implementação da proposta de escola de tempo integral no estado do Pará foram a Resolução n 002/2012 - GS/SEDUC, que dispõe sobre o Projeto Escola de Tempo Integral, e a Resolução $n^{\circ}$ 003/2012 - GS/SEDUC, que dispõe sobre a organização e o funcionamento da escola de tempo integral. Esses são importantes documentos de base que orientaram a materialização da proposta de escola de tempo integral nas escolas públicas estaduais do Pará.

Em 2014 ocorreu a adequação do PEE-2010 ao novo Plano Nacional de Educação definido pela Lei $13.005 / 2014$, que aprovou o PNE. O art. $8^{\circ}$ do referido plano estabeleceu que:

Os Estados, o Distrito Federal e os Municípios deverão elaborar seus correspondentes planos de educação, ou adequar os planos já aprovados em lei, em consonância com as diretrizes, metas e estratégias previstas neste PNE, no prazo de um ano contado da publicação daquela lei (BRASIL, 2014. p. 46).

Assim, em 2015, sob nova política de governo, um novo plano estadual de educação foi aprovado pela Lei ${ }^{\circ} 8.186$, de 23 de junho de 2015, e nele estão expressas as metas e as estratégias para o avanço da educação em tempo integral rumo à meta 6 do PNE II.

A meta 6 do PEE II (2015) expressa o seguinte texto: "oferecer educação em tempo integral em, no mínimo, 30\% das escolas públicas, de forma a atender, pelo menos, 15\% dos(as) alunos(as) da educação básica” (PARÁ, 2015, p. 54). Observamos que a meta 6 do PNE II (2014-2024) foi recepcionada apenas parcialmente pelo estado do Pará, que se definiu 
por aquelas duas distintas obrigações quantitativas, apresentando um percentual menor que a meta nacional.

A contextualização histórica espacial das escolas de tempo integral no estado do Pará, do momento da implantação do projeto piloto em 2012 até o ano de 2014, esteve concentrada, na totalidade, na região metropolitana de Belém. Essa região urbana foi o lócus espacial da introdução do projeto de educação integral, e o ano de 2012 foi, oficialmente, o momento histórico da implantação realizada pela SEDUC-PA (COSTA, 2015).

Esse fato pode ser explicado em função do dinamismo ora apresentado por essa região geográfica; os primeiros projetos pilotos iniciaram nas escolas da capital paraense. Isso facilita a compreensão da cartografia das escolas inseridas no projeto, e a territorialização espacial da dinâmica possibilitou compreender o movimento de evolução, pois a cada ano a expansão do número de escolas inseridas no projeto se deu fortemente nessa região.

Em 2012, ano de implantação do Projeto Escola de Tempo Integral no Pará, somente nove escolas foram inseridas no processo, representando apenas $0,1 \%$ do total de escolas da rede pública, e estavam distribuídas da seguinte forma: sete no município de Belém, duas no município de Ananindeua e uma no município de Marituba. Um número muito reduzido para tão grandioso projeto de dimensão estadual (COSTA, 2015).

A seguir, analisaremos os dados extraídos dos documentos oficias que demonstram o processo de implantação das escolas públicas de tempo integral no estado do Pará.

\section{Lento processo de implantação do programa "escola de tempo integral"}

Para compreendermos o processo de implementação de escolas de tempo integral no estado do Pará, mergulhamos com lentes mais focadas nos documentos oficiais da legislação estadual e nos dados oficiais publicados nos sites da Secretaria de Educação do Estado do Pará (portal SEDUC) e do Ministério da Educação (censo escolar e INEP).

Os dados do censo escolar de 2017 (INEP/MEC) e do balanço de matrículas iniciais de 2018 (SEDUC-PA) demonstram que o processo de implementação das escolas de tempo integral no estado do Pará ainda é muito lento e que o crescimento que se deu ao longo da 
história ainda está muito distante de alcançar a meta 6 do Plano Estadual de Educação (PEE$\mathrm{PA} / 2015)$.

Os números oficiais refletem a deficiência na execução das políticas públicas implementadas com o objetivo de implantar, nas escolas da rede pública, outra concepção de educação (integral) na perspectiva de tempo integral. Como poderemos perceber por meio dos dados oficiais, as políticas públicas demandam muito tempo para se efetivarem no cenário de um estado de grandes dimensões territoriais e enorme diversidade social e cultural como o Pará.

Procuramos, inicialmente, extrair dos documentos oficiais dados sobre as escolas públicas de educação básica paraenses inserindo-as no contexto da rede de ensino nacional. Assim, na Tabela 1 apresentamos a distribuição dos estabelecimentos de ensino da educação básica brasileira pelas diferentes localizações e dependência administrativa com base no censo escolar de 2017:

Tabela 1 - Número de estabelecimentos na educação básica por localização e dependência administrativa em 2017

\begin{tabular}{lrrrr}
\multicolumn{1}{c}{ UNIDADE } & \multicolumn{1}{c}{ BRASIL } & \multicolumn{1}{c}{ NORTE } & \multicolumn{1}{c}{ PARÁ } & \multicolumn{1}{c}{ BELÉM } \\
Total geral & $\mathbf{1 8 4 . 1 4 5}$ & $\mathbf{2 2 . 6 4 6}$ & $\mathbf{1 0 . 9 7 2}$ & $\mathbf{6 8 0}$ \\
Total urbana & 123.451 & 8.381 & 3.694 & 673 \\
Urbana federal & 607 & 69 & 22 & 6 \\
Urbana estadual & 25.109 & 2.365 & 747 & 221 \\
Urbana municipal & 58.354 & 4.291 & 2.060 & 120 \\
Urbana privada & 39.381 & 1.656 & 865 & 326 \\
Total rural & 60.694 & 14.265 & 7.278 & 7 \\
Rural federal & 92 & 8 & 1 & - \\
Rural estadual & 5.410 & 1.577 & 139 & 2 \\
Rural municipal & 54.545 & 12.633 & 7.112 & 5 \\
Rural privada & 647 & 47 & 26 & -
\end{tabular}

Fonte: Portal INEP - Censo Escolar 2017 - Elaborada pelos autores. 
Com base nos dados apresentados na Tabela 1, observamos que o estado do Pará apresenta um número significativo de escolas em todas as localizações e dependências administrativas - são quase 11 mil unidades escolares (10.972 unidades). Um importante dado refere-se ao fato de que a maior parte dos estabelecimentos públicos estaduais de ensino está localizada nas cidades (747 unidades), enquanto no meio rural contamos com apenas 139 estabelecimentos. Particularmente na cidade de Belém, esse percentual atinge aproximadamente 30\% (29,6 \%) das instituições, o que representa algo muito relevante e que merece atenção: grande concentração de escolas públicas estaduais na capital do estado do Pará. Fomos mais além e buscamos informações sobre o número de estabelecimentos e de matrículas nas escolas da educação básica brasileira em tempo integral.

As Tabelas de 2 a 4 nos mostram os dados referentes ao número de estabelecimentos com matrícula em tempo integral por dependência administrativa, de acordo com o censo escolar de 2017. Primeiramente, focamos na realidade brasileira:

Tabela 2 - Número de estabelecimentos na educação básica - percentual de matrículas em tempo integral por dependência administrativa Brasil (2017).

\begin{tabular}{|c|c|c|c|c|c|}
\hline BRASIL & FEDERAL & ESTADUAL & MUNICIPAL & PRIVADA & TOTAL \\
\hline Nenhuma matrícula & 359 & 19.534 & 66.554 & 27.210 & 113.657 \\
\hline Até $5 \%$ das matrículas & 37 & 2.744 & 2.989 & 1.385 & 7.155 \\
\hline Acima de $5 \%$ e até $20 \%$ das matrículas & 37 & 3.242 & 6.501 & 1.346 & 11.126 \\
\hline Acima de $20 \%$ e até $50 \%$ das matrículas & 78 & 2.494 & 12.649 & 1.455 & 16.676 \\
\hline Acima de $50 \%$ e até $70 \%$ das matrículas & 84 & 766 & 7.118 & 712 & 8.680 \\
\hline Mais de $70 \%$ das matrículas & 104 & 1.739 & 17.088 & 7.920 & 26.851 \\
\hline Total de estabelecimentos & 699 & 30.519 & 112.899 & 40.028 & 184.145 \\
\hline $\begin{array}{l}\text { Total de estabelecimentos com } \\
\text { matrícula em tempo Integral }\end{array}$ & 340 & 10.985 & 46.345 & 12.818 & 70.488 \\
\hline
\end{tabular}

Fonte: Portal INEP - Censo Escolar 2017 - Elaborada pelos autores.

Da mesma forma, com base nos dados apresentados na Tabela 2, percebemos que, no Brasil, o número de estabelecimentos com algum percentual de matrícula em tempo integral ainda é muito reduzido. De todas as instituições de educação básica existentes em todas as esferas no Brasil no ano de 2017 (184.145), apenas 70.488 apresentaram algum percentual de matrícula em tempo integral. Esse número correspondia a pouco mais de $38 \%$ do total dos estabelecimentos. Esse percentual ainda se encontra muito abaixo do previsto na meta 6 - 
tempo integral - do PNE de 2014, que é “oferecer educação em tempo integral em, no mínimo, $50 \%$ das escolas públicas, de forma a atender, pelo menos, 25\% dos(as) alunos(as) da educação básica” (BRASIL, 2017, p. 59-60).

No Brasil, a esfera administrativa que alcança os melhores percentuais de estabelecimentos com matrícula em tempo integral é a pública municipal, que, em 2017, representava $66 \%$ das matrículas em tempo integral em todo o país. Isso se deve ao grande número de creches e pré-escolas em tempo integral existentes nos municípios.

Para melhor compreensão do objeto do estudo, filtramos um pouco mais os dados e buscamos detalhar a representatividade das escolas públicas estaduais na oferta de matrículas em tempo integral no cenário do estado do Pará.

A seguir, na Tabela 3, apresentamos a realidade do número de estabelecimentos na educação básica com matrículas em tempo integral no Estado do Pará, de acordo com os dados do censo escolar de 2017.

Tabela 3 - Número de estabelecimentos na educação básica - percentual de matrículas em tempo integral por dependência administrativa - estado do Pará (2017)

\begin{tabular}{|c|c|c|c|c|c|}
\hline PARÁ & FEDERAL & ESTADUAL & MUNICIPAL & PRIVADA & TOTAL \\
\hline Nenhuma matrícula & 16 & 791 & 7.359 & 825 & 8.991 \\
\hline Até 5\% das matrículas & 1 & 51 & 154 & 21 & 227 \\
\hline $\begin{array}{l}\text { Acima de } 5 \% \text { e até } 20 \% \\
\text { das matrículas }\end{array}$ & 2 & 12 & 307 & 13 & 334 \\
\hline $\begin{array}{l}\text { Acima de } 20 \% \text { e até } 50 \% \\
\text { das matrículas }\end{array}$ & 2 & 21 & 593 & 10 & 626 \\
\hline $\begin{array}{l}\text { Acima de } 50 \% \text { e até } 70 \% \\
\text { das matrículas }\end{array}$ & - & 5 & 336 & 2 & 343 \\
\hline $\begin{array}{l}\text { Mais de } 70 \% \text { das } \\
\text { matrículas }\end{array}$ & 2 & 6 & 423 & 20 & 451 \\
\hline Total de estabelecimentos & 23 & 886 & 9.172 & 891 & 10.972 \\
\hline $\begin{array}{l}\text { Total de estabelecimentos } \\
\text { com matrícula em tempo } \\
\text { integral }\end{array}$ & 7 & 95 & 1.813 & 66 & 1.981 \\
\hline
\end{tabular}

Fonte: Portal INEP - Censo Escolar 2017 - Elaborada pelos autores. 
Os dados da tabela nos permitem inferir que, no estado do Pará, o número de estabelecimentos com matrícula em tempo integral, no ano de 2017, nas diferentes esferas, também foi proporcionalmente baixo se comparado com o número de estabelecimentos existentes. Do total de estabelecimentos (10.972), apenas 1.981, em todas as esferas, apresentaram algum percentual de matrículas em tempo integral, número que representa menos de $20 \%$ deles.

Ao levarmos, entretanto, em consideração apenas os estabelecimentos da esfera pública estadual, que é a esfera coberta pelas políticas públicas estaduais por meio do Projeto Escola de Tempo Integral no Pará, esse percentual é ainda mais preocupante. Do total de escolas públicas estaduais (886), somente 95 estabelecimentos apresentaram algum percentual de matrículas em tempo integral em 2017, o que equivale a apenas 11\% das instituições. Esse percentual está muito aquém daquele estabelecido pela meta 6 do PEE (2015), que é atingir $30 \%$ das escolas, com 15\% dos alunos matriculados em tempo integral, até o ano de 2024.

Se considerarmos o percentual de estabelecimentos com matrículas em tempo integral em todas as esferas no Estado, também está muito inferior ao estabelecido pela meta 6 do atual PEE (2015), fato que pode ser explicado por um conjunto de fatores, como a política pública ineficiente implantada desde 2008 e reformulada em 2012 e o baixo nível socioeconômico apresentado pela maioria das famílias no estado do Pará.

Com lentes mais focalizadas avançamos um pouco mais e buscamos contextualizar o cenário das escolas de tempo integral no contexto da capital do estado. Esse cenário é muito importante, pois retrata a realidade das escolas de tempo integral, em termos quantitativos, no município lócus da implementação do Programa Escola Públicas de Tempo Integral do Estado do Pará. A seguir, na Tabela 4, apresentamos a realidade dos números para o cenário das escolas de tempo integral no município de Belém. 
Tabela 4 - Número de estabelecimentos na educação básica - percentual de matrículas em tempo integral por dependência administrativa - município de Belém (2017)

\begin{tabular}{|c|c|c|c|c|c|}
\hline BELÉM & FEDERAL & ESTADUAL & MUNICIPAL & PRIVADA & TOTAL \\
\hline Nenhuma matrícula & 4 & 191 & 54 & 304 & 553 \\
\hline Até $5 \%$ das matrículas & 1 & 10 & 2 & 6 & 19 \\
\hline $\begin{array}{l}\text { Acima de } 5 \% \text { e até } 20 \% \text { das } \\
\text { matrículas }\end{array}$ & 1 & 5 & 17 & 5 & 28 \\
\hline $\begin{array}{l}\text { Acima de } 20 \% \text { e até } 50 \% \text { das } \\
\text { matrículas }\end{array}$ & - & 9 & 16 & 4 & 29 \\
\hline $\begin{array}{l}\text { Acima de } 50 \% \text { e até } 70 \% \text { das } \\
\text { matrículas }\end{array}$ & - & 4 & 4 & 2 & 10 \\
\hline Mais de $70 \%$ das matrículas & - & 4 & 32 & 5 & 41 \\
\hline Total de estabelecimentos & 6 & 223 & 125 & 326 & 680 \\
\hline $\begin{array}{l}\text { Total de estabelecimentos } \\
\text { com matrícula em tempo } \\
\text { integral }\end{array}$ & 2 & 32 & 71 & 22 & 127 \\
\hline
\end{tabular}

Fonte: Portal INEP - Censo Escolar 2017 - Elaborada pelos autores.

No município de Belém, o cenário apresenta as seguintes características: o número de estabelecimentos com matrícula em tempo integral, no ano de 2017, entre todas as diferentes esferas, também foi proporcionalmente baixo se comparado com o total de estabelecimentos existentes no município. Dos 680 estabelecimentos, apenas 127, em todas as esferas, apresentaram algum percentual de matrícula em tempo integral. Esse número representa cerca de $20 \%$ de todos os estabelecimentos, sendo considerado baixo em se tratando de escolas da rede de ensino da capital do estado.

Da mesma forma, se levarmos em consideração apenas os estabelecimentos da esfera pública estadual, que é a esfera coberta pelas políticas públicas por meio do Projeto Escola de Tempo Integral no Pará, esse percentual é ainda mais preocupante. Do total de escolas púbicas estaduais na capital (223), apenas 32 apresentaram algum percentual de matrículas em tempo integral em 2017, o que equivale a pouco mais de $14 \%$ das instituições no município sede do governo do estado. Esse percentual, mesmo na capital, também está muito aquém daquele estabelecido pela meta 6 do PEE (2015), que é atingir 30\% das escolas com pelo menos $15 \%$ dos alunos matriculados em tempo integral.

Esse fato pode ser explicado também pelo conjunto de fatores anteriormente mencionados, como a política pública deficitária implantada desde 2008 e que foi reformulada em 2012, o reduzido número de escolas estaduais na capital optantes pelo projeto Escola de 
Tempo Integral no Pará e o baixo nível socioeconômico apresentado pelas famílias no município capital.

Ressaltamos que a esfera pública municipal em Belém é a que apresenta os melhores números em relação aos estabelecimentos com matrículas em tempo integral. Dos 125 estabelecimentos existentes em 2017, apenas 71 unidades, geralmente Unidades de Educação Infantil (UEI), com creches e pré-escolas, apresentavam matrículas em tempo integral. Esse número representa cerca de $60 \%$ dos estabelecimentos públicos municipais.

Destacamos aqui um fato que consideramos relevante. Até mesmo no setor privado, no município de Belém, a realidade chama a atenção, pois, de todos os estabelecimentos privados existentes (326), apenas 22 escolas apresentaram matrículas em tempo integral com algum percentual de aluno, de acordo com o censo escolar de 2017. Esse número equivale a menos de $7 \%$ das escolas da rede privada da capital, sendo esse percentual quase semelhante àquele apresentado no setor privado em todo o estado do Pará (8\%). Em relação ao total de estabelecimentos com matrículas em tempo integral (127), em todas as esferas da capital, as 22 escolas privadas representam 17\%, um percentual ainda baixo se considerarmos a infraestrutura das escolas, o nível socioeconômico das famílias e o número elevado de estabelecimentos privados (326) existentes hoje na capital. Esse número de estabelecimentos privados corresponde a $48 \%$ dos estabelecimentos de ensino da cidade de Belém (680).

Apontamos entre as prováveis causas desses baixos números de matrícula em tempo integral nos estabelecimentos da rede privada da cidade o padrão socioeconômico das famílias, mesmo entre aquelas que frequentam essa rede de ensino, pois os custos adicionais de escola de tempo integral não são de fácil resolução no orçamento familiar, bem como a falta de interesse ou desconhecimento por uma escola de tempo integral apesar da dinâmica da vida urbana moderna, dotada de informações a todos. A seguir focalizaremos a análise nos números relativos ao período de vigência do PEE II/2015.

\section{Os avanços na implantação das escolas de tempo integral no}

\section{Pará}

Por fim, levantamos os números oficiais que traduzem o processo de implementação de escolas de tempo integral na rede pública estadual do Pará para o período de vigência do 
PEE-PA II. Para esse fim, a Tabela 6 apresenta o número de escolas públicas estaduais, por município, com matrículas em tempo integral no estado do Pará no período de 2015 a 2018:

Tabela 5 - Número de estabelecimentos públicos com matrículas em tempo integral SEDUC - estado do Pará (2015-2018)

\begin{tabular}{|c|c|c|c|c|c|c|c|c|}
\hline \multirow{2}{*}{ Município } & \multicolumn{2}{|l|}{2015} & \multicolumn{2}{|l|}{2016} & \multicolumn{2}{|l|}{2017} & \multicolumn{2}{|l|}{2018} \\
\hline & $\begin{array}{l}\mathrm{N}^{\mathrm{o}} \\
\text { Escola }\end{array}$ & Matrícula & $\begin{array}{l}\mathrm{N}^{\mathrm{o}} \\
\text { Escola }\end{array}$ & Matrícula & $\begin{array}{l}\mathrm{N}^{\mathrm{o}} \\
\text { Escola }\end{array}$ & Matrícula & $\begin{array}{l}\mathrm{N}^{\mathrm{o}} \\
\text { Escola }\end{array}$ & Matrícula \\
\hline Ananindeua & 01 & 127 & 01 & 112 & 03 & 347 & 03 & 473 \\
\hline Barcarena & - & - & - & - & - & - & 01 & 87 \\
\hline Belém & 10 & 1.855 & 11 & 2.292 & 18 & 3.618 & 16 & 4.359 \\
\hline Benevides & 01 & 81 & 01 & 91 & 01 & 62 & 01 & 61 \\
\hline Bragança & - & - & - & - & - & - & 03 & 407 \\
\hline Castanhal & 01 & 58 & 01 & 57 & 01 & 46 & 01 & 22 \\
\hline Marabá & - & - & - & - & 04 & 758 & 04 & 1.397 \\
\hline Maracanã & - & - & - & - & - & - & 01 & 99 \\
\hline Santarém & - & - & - & - & - & - & 02 & 119 \\
\hline Subtotal & 13 & 2.121 & 12 & 2.552 & 27 & 4.831 & 32 & 7.024 \\
\hline
\end{tabular}

Fonte: Portal SEDUC - 2018 - Elaborada pelos autores.

Os valores constantes na Tabela 6 nos permitem afirmar que o número de escolas públicas estaduais que aderiram ao Projeto Escola de Tempo Integral no Estado do Pará ainda é muito reduzido se comparado com a grande quantidade de escolas existentes na rede pública estadual.

O número de municípios que adotaram tal política (apenas nove) é pequeno em comparação com o total de municípios que formam o estado do Pará - ao todo, 144.

Constatamos que, no ano de 2018, apenas 32 escolas apresentavam matrículas em tempo integral, em que pese que, para o período compreendido entre 2015 e 2018, verificamos o aumento em mais de $100 \%$ no número de estabelecimentos e de alunos matriculados em tempo integral. Os dados do Balanço de Matrículas SEDUC-PA/18 apresentados na Tabela 7 a seguir confirmam essa relação quantitativa. 
Tabela 6 - Escolas públicas*/número de matrículas em tempo integral 2018 - SEDUC Estado do Pará

\begin{tabular}{|c|c|c|c|}
\hline $\begin{array}{l}\text { Total de } \\
\text { municípios }\end{array}$ & Total de escolas & Total de anexos & $\begin{array}{c}\text { Total de escolas/matrículas } \\
\text { em tempo integral }\end{array}$ \\
\hline 144 & 868 & 85 & 32 \\
\hline
\end{tabular}

Fonte: Portal SEDUC - 2018 - Elaborada pelos autores.

Percebemos que, das 868 escolas públicas estaduais do Pará, somente 32, em 2018, apresentaram matrícula em tempo integral, o representa menos de 5\% do total $(3,6 \%)$. Esse dado demonstra um distanciamento muito grande em relação à própria meta 6 estabelecida pelo PEE-PA (2015), que prevê atingir até 30\% das escolas e 15\% dos alunos em matrícula em tempo integral, o que deve ser alcançado até 2024.

Essa particularidade não é diferente quando analisamos os números específicos na região da Unidade Regional de Educação (URE) - Belém, situada na capital do estado do Pará, cidade que, originalmente, concentrou a maioria das escolas em tempo integral desde 2012. Vejamos a Tabela 8, que nos apresenta os dados mais detalhados.

Tabela 7 - Escolas públicas*/número de matrícula 2018 - SEDUC - URE-19A - Belém

\begin{tabular}{l|l|c|l}
\hline $\begin{array}{l}\text { Total de } \\
\text { municípios }\end{array}$ & $\begin{array}{l}\text { Total de } \\
\text { escolas* }\end{array}$ & Total de anexos & $\begin{array}{l}\text { Total de } \\
\text { ESCOLAS/MATRÍCULA } \\
\text { EM TEMPO INTEGRAL }\end{array}$ \\
\hline 5 & 347 & 08 & 20 \\
$-_{* \text { Contabilizando escolas de escolarização e exclusivamente de atendimento especializado. }}$
\end{tabular}

Fonte: Portal SEDUC - 2018 - Elaborada pelos autores.

Da mesma forma observamos que o número de escolas que adotaram o tempo integral na rede pública estadual na capital é muito reduzido em comparação com o total de escolas. Das 347 escolas públicas estaduais pertencentes à URE-19A - Belém, somente 20 escolas apresentaram dados de matrículas em tempo integral no ano de 2018. Esse número representa um percentual inferior a $6 \%(5,7 \%)$ das escolas existentes na região da URE-19A, que 
envolve a capital do estado do Pará e mais quatro municípios; assim, ainda distante da meta estabelecida pelo PEE-PA (2015).

O levantamento dos dados referentes às escolas de tempo integral na rede pública do estado do Pará foi muito importante para que pudéssemos chegar ao comparativo com os números das escolas da rede privada em tempo integral no contexto paraense e, em particular, na cidade de Belém, que foi objeto de estudo da nossa dissertação do mestrado.

Neste percurso histórico desafiante traçado sobre o surgimento, nos últimos anos, das escolas de tempo integral no estado do Pará e, principalmente, na cidade de Belém, não consideramos a concepção de educação integral anunciada pelos estabelecimentos de ensino das diferentes esferas, seja na pública federal, estadual, municipal ou na esfera privada. Assim, levantamos, para efeito de estudo, apenas a condicionante tempo integral e sua relação com o percentual de matrículas realizadas no mesmo período histórico analisado.

\section{Considerações finais}

A partir dessa contextualização mais contemporânea sobre o processo de implementação das escolas de tempo integral no estado do Pará, buscamos resposta para a questão proposta para este estudo: como se deu o processo de implantação do Programa de Escola de Tempo Integral na rede pública do estado do Pará?

A reflexão nos leva a inferir, após esse breve levantamento histórico de experiências de escola de tempo integral no estado do Pará, que a forma como as políticas vêm sendo implementadas no campo das escolas tem se distanciado daqueles objetivos previstos nos planos - nacional e estadual - de educação, principalmente no que diz respeito aos fins da educação: o desenvolvimento de uma educação de qualidade social para todos que possibilite o mais amplo desenvolvimento dos alunos.

É possível que as inúmeras problemáticas estruturais que as escolas apresentam diante da fragilidade das políticas públicas, do pouco ou nenhum investimento público na manutenção dos espaços escolares, o que culminou numa total falta de estrutura física, qualificação para monitores e professores, falta de esclarecimentos dos sujeitos quanto aos conceituais e metodologia sobre educação integral em tempo integral, tenham paralisado as condições para criar possibilidades de executar um programa que tivesse a educação integral 
como horizonte a ser efetivado nas experiências atuais nas escolas de tempo integral no estado do Pará.

O sentido de integrar, em 2015, as escolas de tempo integral do estado ao PME (BRASIL, 2007) foi uma estratégia para alavancar o Programa Estadual; entretanto, de certa forma, a interveniência dos pressupostos do PME comprometeu a implementação do programa de escolas de tempo integral no Pará, alterando com isso a feição própria do plano estadual. $\mathrm{O}$ atrelamento ao aporte financeiro vinculou as nossas escolas a um formato tempoespaço sugerido no Plano Nacional, e isso fez que perdêssemos a nossa especificidade regional.

Ressaltamos que não tivemos acesso a uma avaliação oficial sobre o alcance das metas previstas no PEE (PARÁ, 2015), nem mesmo a confirmação se existe alguma forma de acompanhamento dessas metas, entretanto estudos recentes de dissertações de mestrado, entre eles os de Costa (2015), Sousa (2016), Lélis (2017), Alves (2018), Cardoso (2018) e Silva (2019), apontam falhas no processo de implementação das escolas de tempo integral em nosso estado. Os principais problemas que observamos elencados por esses estudos são a deficiente infraestutura física e de pessoal das escolas, parcos investimentos financeiros e divergências conceituais em relação às práticas educativas realizadas no tempo integral, entre outros.

Neste cenário, tempo e espaço são elementos que necessitam ser ressignificados. Em relação à organização do tempo e do espaço, o programa de escola de tempo integral no Pará (2015) não foi inovador, pois o mesmo apresentou-se falho em relação à organização do trabalho escolar. As tomadas de decisão sempre foram mais um acaso da gestão pública interessada quando propunham estratégias e metas que visavam à preparação para as avaliações externas e à manipulação política dos resultados do que propriamente para a formação integral dos alunos (LÉLIS, 2017).

Desse modo, embora no discurso do jogo político os programas indicassem avanços, o que se percebeu foi que o Programa Escola de Tempo Integral no Pará apresentou, desde o início de sua implantação, inúmeras fragilidades de toda ordem. As diretrizes necessitam ser reavaliadas e os investimentos melhorados pela política pública em curso. As escolas clamam por aumento dos investimentos para a melhoria da infraestrutura física e para garantir a qualificação de todos os profissionais envolvidos diretamente com o processo. Entendemos que educação de qualidade exige o indispensável tripé: recursos financeiros, melhor aparelhamento das escolas e valorização docente. 
Acreditamos, portanto, que a efetivação da educação no tempo integral pressupõe mudança dos espaços escolares e, mesmo que o tempo seja ampliado nas escolas, teríamos de buscar outros equipamentos que fossem capazes de abrigar as demandas inerentes à ideia de formação integral. Teríamos que ter outra escola com conformação para garantir essa concepção de educação, embora, saibamos que os desafios da implementação de escolas de tempo integral de qualquer programa demonstrem limites e fragilidades.

\section{Referências}

ALVES, A. C. S. Gastos e Custos do Processo de Implementação do Ensino Médio em Tempo Integral no Pará (2012-2015). 2018. 178 f. Dissertação (Mestrado em Educação) Universidade Federal do Pará, Belém, 2018.

BARDIN, L. Análise do Conteúdo. São Paulo: Edições 70, 2011.

BRASIL. Decreto $\mathbf{n}^{\mathbf{0}}$ 6.253, de 13 de novembro de 2007. Dispõe sobre o Fundo de Manutenção e Desenvolvimento da Educação Básica e de Valorização dos Profissionais da Educação - FUNDEB, regulamenta a Lei nº 11.494, de 20 de junho de 2007, e dá outras providências. Brasília-DF, 2007b.

BRASIL. Lei $\mathrm{n}^{\circ}$ 9.394, de 20 de dezembro de 1996, que estabelece as diretrizes e bases da educação nacional. 14. Ed. - Brasília: Câmara dos Deputados, Edições Câmara, 2017a.

BRASIL. Lei $\mathbf{n}^{0}$ 10.172, de 09 de janeiro de 2001. Aprova o Plano Nacional de Educação e dá outras providências. Brasília-DF: Diário Oficial da União, 2001.

BRASIL. Lei no 13.005, de 25 de junho de 2014. Aprova o Plano Nacional de Educação PNE e dá outras providências. Brasília-DF: Câmara dos Deputados. Série Legislação, 2017b.

BRASIL. Governo Federal. Portaria Interministerial $\mathbf{n}^{\circ}$ 17, de 24 de abril de 2007. Institui o Programa Mais Educação, que visa fomentar a educação integral de crianças, adolescentes e jovens, por meio do apoio a atividades socioeducativas no contraturno escolar. Ministério da Educação. Brasília-DF, 2007a.

BRASIL. Programa Mais Educação. Educação Integral: texto referência para o debate nacional. Série Mais Educação. Brasília: Ministério da Educação/SECAD, 2009a.

BRASIL. Programa Mais Educação. Gestão intersetorial no território. Série Mais Educação. Brasília: Ministério da Educação/SECAD, 2009b.

BRASIL. Programa Mais Educação. Rede de Saberes Mais Educação: pressupostos para Projetos Pedagógicos de Educação Integral. Série Mais Educação. Brasília: Ministério da N Educação/SECAD, 2009c. 
CARDOSO, C. S. Educação Integral e(m) Tempo Integral em Belém-PA: Concepções em Processo na Escola Municipal Rio Maguary. 2018. 175 f. Dissertação (Mestrado em Educação) - Universidade Federal do Pará, Belém, 2018.

CAVALIERE, A. M. V. Escolas de Tempo Integral: uma idéia forte, uma experiência frágil. In: COELHO, L. M. C. da C CAVALIERE, A. M. V. (org.). Educação Brasileira e(m) Tempo Integral. Petrópolis - RJ: Vozes, 2002, p. 93-111.

CAVALIERE, A. M. V. Escolas de tempo integral versus alunos em tempo integral. In: MAURÍCIO, L. V. (org.). Educação integral em tempo integral. Em Aberto, Brasília-DF, v. 22, n. 80, p. 51-63, abr. 2009a.

CAVALIERE, A. M. V. Notas sobre o conceito de educação integral. In: COELHO, L. M. C. da C. (org.). Educação Integral em Tempo Integral: estudos e experiências em processo. Petrópolis, RJ: DP et Alii. FAPERJ, 2009b, p. 41-51.

CAVAliERE, A. M. V.; COELHO, L. M. C. da C. Pesquisa sobre Educação Integral e Tempo Integral: Histórias, Políticas e Práticas. Curitiba: CRV, 2017.

CAVAliERE, A. M. V. Tempo de Escola e Qualidade na Educação Pública, Educação e Sociedade. Campinas, v. 28, n. 100 - Especial, p. 1015-1035, out. 2007.

COSTA, C. N. O Projeto de Tempo Integral no Pará: caso da Escola Miriti. Dissertação (Mestrado em Educação) - Universidade Federal do Pará, Belém, 2015.

COELHO, L. M. C. da C. Educação Integral: histórias, políticas e práticas. Rio de Janeiro: Editora Rovelle, 2013.

COELHO, L. M. C. da C. (org.). Educação Integral em tempo integral: estudos e experiências em processo. Petrópolis, RJ: DP et Alii; Rio de Janeiro: FAPERJ, 2009.

COELHO, L. M. C. da C. Tempos e Espaços Escolares: experiências, políticas e debates no Brasil e no mundo. Rio de Janeiro: Ponteio, FAPERJ, 2014.

COELHO, L. M. C. da C.; CAVALIERE, A. M. V. (org.). Educação Brasileira e(m) Tempo Integral. Petrópolis: Vozes, 2002.

COELHO, L. M. C. da C.; PORTILHO, D. B. Educação Integral, tempo e políticas públicas: reflexões sobre concepções e práticas. In: COELHO, L. M. C. da C. (org.) Educação Integral e(m) tempo integral: estudos e experiências em processo. Petrópolis, RJ: FAPERJ, 2009, p. 89-100.

COELHO, L. M. C. da C.; SIRINO, M. B. Concepções de Educação Integral, Gestão do Tempo e Projeto (s) de Sociedade: um debate (mais do que) atual. In: FERREIRA, A. G.; BERNARDO, E. da S.; MENEZES, J. S. da S. (org.). Políticas e Gestão em Educação em Tempo Integral: desafios contemporâneos. Curitiba: CRV, 2018. p. 137-161.

FRANCO, M. L. P. B. Análise de conteúdo. 4. ed. Brasília: Liber Livro, 2012.

GADOTTI, M. Educação Integral no Brasil: inovações em processo. São Paulo: Editora e Livraria Instituto Paulo Freire, 2013. 
GUARÁ, I. M. F. R. É imprescindível educar integralmente. In: Educação Integral. Cadernos Cenpec, São Paulo, n. 2, p. 15-24, jul./dez. 2006.

\section{LELIS, L. S. C. Saberes e Fazeres da Gestão Pedagógica e sua Relação com a} apropriação dos resultados do IDEB. 147 f. Dissertação (Mestrado em Educação) Universidade Federal do Pará, Belém, 2017.

LIBÂNEO, J. C. Valerá a pena investir dinheiro público na escola de tempo integral? Mesa Redonda no colóquio da Linha Teorias da Educação, do Mestrado em Educação da Universidade Católica de Goiás, novembro de 2006.

MAURÍCIO, L. V. Políticas públicas, tempo, escola. In: COELHO, L. M. C. da C. (org.). Educação Integral em tempo integral: estudos e experiências em processo. Petrópolis, RJ: DP et Alii; Rio de Janeiro: FAPERJ, 2009, p. 53-68.

MOLL, J. Série Mais Educação. Educação Integral: texto referência para o debate nacional. Brasília: MEC, SECAD, 2009b.

MOLL, J. Série Mais Educação. Redes de Saberes Mais Educação: pressupostos para projetos pedagógicos de Educação Integral. 1. ed. Brasília: Ministério da Educação, 2009a.

MOLL, J. et al. Caminhos da Educação Integral no Brasil: direitos a outros tempos e espaços educativos. Porto Alegre: Penso, 2012.

PARÁ. A Educação Básica no Pará: elementos para uma política democrática e de qualidade Pará todos. Secretaria de Estado de Educação. Belém, 2008a.

PARÁ. Secretaria de Estado de Educação. A Política de Educação Básica do Estado do Pará. Belém, 2008b.

PARÁ. Lei no 7.441, de 2 de julho de 2010. Aprova o Plano Estadual de Educação - PEE e dá outras providências. Governo do Estado do Pará. Secretaria de Estado de Educação -Seduc: Belém, 2010.

PARÁ. Lei no 8.186, de 23 de junho de 2015. Aprova o Plano Estadual de Educação - PEEII e dá outras providências. Governo do Estado do Pará. Secretaria de Estado de Educação Seduc: Belém, 2015.

PARÁ. Resolução n⿳0 002/2012 - GS/SEDUC que dispõe sobre o Projeto Escola de Tempo Integral. SEDUC-PA: Belém, 2012a. Disponível em: https://www.jusbrasil.com.br/diarios/36529677/doepa-caderno-5-27-04-2012-pg-2. Acesso em: 20 jul. 2018.

PARÁ. Resolução n⿳0 003/2012 - GS/SEDUC que dispõe sobre a Organização e o Funcionamento da Escola de Tempo Integral. SEDUC-PA: Belém, 2012b. Disponível em: https://www.jusbrasil.com.br/diarios/36529677/doepa-caderno-5-27-04-2012-pg-2. Acesso em: 20 jul. 2018.

PARÁ. Portal Seduc. Secretaria de Educação do Estado do Pará. Governo do Estado do Pará. Disponível em: http://www.seduc.pa.gov.br/site/seduc. Acesso em: 20 jul. 2018. 
PARO, V. H. et al. Escola de Tempo Integral: desafio para o ensino público. São Paulo: Cortez: Autores Associados, 1988.

RIBEIRO, Darcy. O livro dos CIEPs. Rio de Janeiro: Bloch, 1986.

SILVA, R. do S. M. da. A Educação Integral em Tempo Integral na escola privada: experiências pioneiras na cidade de Belém. 2019. 163 f. Dissertação (Mestrado em Educação)

- Universidade Federal do Pará, Belém, 2019.

SOUSA, L do E. S. Políticas de Ampliação da Jornada Escolar: a implantação do programa Mais Educação em Igarapé-Miri/PA. 2016. 187 f. Dissertação (Mestrado em Educação) - Universidade Federal do Pará, Belém, 2016.

Enviado em: 15/07/2019

Aprovado em: 26/03/2021

Publicado em: 15/06/2021 